\title{
Frozen rumen fluid as microbial inoculum in the two-stage in vitro digestibility assay of ruminant feeds
}

\author{
N. Denek ${ }^{1 \#}$, A. Can ${ }^{2}$ and M. Avci ${ }^{1}$ \\ ${ }^{1}$ Faculty of Veterinary Medicine, University of Harran, Sanliurfa, Turkey \\ ${ }^{2}$ Faculty of Agriculture, University of Harran, Sanliurfa, Turkey
}

\begin{abstract}
This study was carried out to investigate the possibility of using frozen rumen fluid (RF) as an inoculum source in the determination the in vitro dry matter digestibility (IVDMD) of ruminant feeds. In the first experiment six roughages (barley straw, wheat straw, lentil straw, wheat silage, maize silage and lucerne hay) and six different compound feeds (two dairy cattle, two beef cattle, one ram lamb and one lamb finishing compound feeds) were chosen as test material. Two different types of cryoprotectants (5\% glycerol vs. 5\% dimethyl sulfoxide, DMSO) and two types of freezing methods (liquid nitrogen vs. deep freezing) were used to preserve the RF. Fresh RF was used as the control. In response to the results of the first experiment, a second experiment was conducted to establish if microbial digestibility could be improved by extending the duration of incubation of the roughages from 48 to 60,72 or $96 \mathrm{~h}$. When using the RF inoculum treated with 5\% DMSO and frozen in liquid nitrogen, the IVDMD of the compound feeds were similar to those of the control. However, when the 5\% DMSO treated inoculum was frozen in the deep freezer, some of the compound feeds had similar IVDMD values to the control but not all. Lower IVDMD values were recorded when glycerol was used as a cryoprotectant. In the case of the roughages the use of both freezing methods and cryoprotectants resulted in lower IVDMD values compared to the control. In the second experiment the increasing of the duration of incubation of roughages from 48 to $72 \mathrm{~h}$ improved their IVDMD to values similar to that of the control. This suggested that the length of the incubation of roughages should be $72 \mathrm{~h}$ instead of $48 \mathrm{~h}$ when using inocula treated with 5\% DMSO as a cryoprotectant and frozen in a deep freezer. However, further research is required before frozen RF can be recommended as source of inoculum.
\end{abstract}

Keywords: Sheep inoculum, incubation length, freezing method, cryoprotectant

\#Corresponding author. E-mail: nihatdenek@hotmail.com

\section{Introduction}

Determining nutrient digestibility of feeds with in vivo and in vitro methods necessitates the use of live intact or surgically modified animals. Although in vivo digestibility is the single most important method of characterizing the nutritional value of feedstuffs, its execution is expensive, labour intensive, timeconsuming and a large amount of feedstuff is required (Van der Baan et al., 2004). The in vitro procedure is a simple, cheap, convenient and reliable method for measuring feed digestibility in ruminants. However, lack of ruminally cannulated animals in commercial or state feed evaluation laboratories restricts the in vitro evaluation of feedstuffs. The necessity of keeping fistulated animals to provide the inoculum encompasses a number of challenges such as surgical facilities, constant care to avoid infections, long-term maintenance and ethical issues of using these animals (Mauricio et al., 1999). Faeces, lyophilized rumen fluid (RF) and enzyme based methods have been evaluated as alternatives to fresh RF inocula, but results were inconsistent (Krishnamoorthy et al., 1983; Mauricio et al., 2001; Mould, 2003; Denek \& Can, 2007). Preservation of RF at low temperatures has been suggested as a practical alternative (Hervas et al., 2005), though specific conditions are required for the optimal activity of ruminal microorganisms, such as an anaerobic medium, a temperature of $39^{\circ} \mathrm{C}$ and moisture. These constraints cause difficulties in preserving microorganism under in vitro culture and deep-frozen conditions.

The use of frozen rumen inocula protected with a cryoprotectant has not been investigated in the determination of the in vitro dry matter digestibility (IVDMD) of feedstuffs. Cryoprotectants (glycerol, propylene glycol, ethylene glycol, sucrose and trehalose) act at cell membrane level by limiting the effect of cell dehydration during freezing in which the freezing point of cellular liquids is lowered and vitrification 
rather than intracellular ice crystal formation is promoted (Mazur, 1984; Tanasawa, 1998; Nsabimana et al., 2003). Luchini et al. (1996a; b) demonstrated that mixed ruminal microorganism, preserved by freezing them with $5 \%$ glycerol, can be used as the inoculum source for the in vitro estimation of ruminal protein digestion. However, cryoprotectants are more commonly used for preserving ruminal protozoa than mixed ruminal microorganism. Kisidayova et al. $(2005 ; 2006)$ demonstrated that frozen ruminal protozoa protected with $5 \%$ dimethyl sulfoxide (DMSO) had high survival rates. Abdel-Aziz et al. (2007) compared cryopreservation of rumen ciliates using a two-step freezing technique and 4, 5 or $6 \%$ of DMSO, glycerol and ethylene glycol as cryoprotectants. The highest viable protozoa were produced with the addition of DMSO at all concentrations.

The aim of this study was to investigate the possibility of using frozen RF (liquid nitrogen vs. deep freeze) with cryoprotectants (5\% glycerol vs. $5 \%$ DMSO) as an inoculum source for determining the IVDMD of ruminant feeds.

\section{Materials and Methods}

This study was conducted in accordance with the Harran University Animal Experimentation Local Ethics Committee (HRU-AELEC) 06-2009 for protection of animals used for experimental and other scientific purposes. In vitro digestibility studies were conducted on 12 feeds, six roughages and six commercial compound feeds. The roughages were barley straw, wheat straw, lentil straw, wheat silage, maize silage and lucerne hay, and the compound feeds comprised of two dairy cattle, two beef cattle, one ram lamb and one lamb finishing commercial feeds supplied by compound feed companies close to the Harran University. All feed samples were ground in a Wiley mill through a $1 \mathrm{~mm}$ screen.

The treatments were: Group I: Fresh RF as the control; Group II: Filtered RF frozen in liquid N with $5 \%$ DMSO (v/v) as cryoprotectant; Group III: Filtered RF frozen in liquid N with $5 \%$ glycerol (v/v) as cryoprotectant; Group IV: RF plus 5\% of DMSO (v/v) and stored in a deep freeze, and Group V: RF plus 5\% of glycerol (v/v) stored in a deep freeze.

Four ruminally cannulated Awassi rams ( $51.5 \pm 1.50 \mathrm{~kg}$ live weight) of the research farm at the Harran University were fed twice a day at $08: 00$ and $17: 00$ on a diet consisting of $40 \%$ concentrate and $60 \%$ lucerne. On day 20 fresh RF was collected from the cannulated animals before morning feeding. Collection was done with the aid of an electrically operated portable hand vacuum pump and the RF from the four donor animals was composited after collection. The collected RF contained not only liquid but also the solid fraction of rumen content. The rumen fluid was transported to the laboratory without delay in pre-warmed plastic containers under $\mathrm{CO}_{2}$ and at $39^{\circ} \mathrm{C}$. The composited RF was filtered through four layers of cheese cloth prior to preparation.

Preparation consisted of dispensing the RF into in vitro tubes containing the cryoprotectant, using five replicate tubes per treatment. The tubes were placed in a cooling water bath containing ice and kept refrigerated at $+4{ }^{\circ} \mathrm{C}$ for 30 min (equilibration time). Tubes for liquid $\mathrm{N}$ freezing were held horizontally (increment surface area for faster thawing) in nitrogen vapour until frozen, using a special sieve. These tubes were then immersed in a liquid nitrogen tank at $-196{ }^{\circ} \mathrm{C}$ and kept for a month. For deep freezing, the tubes were placed horizontally in a deep freezer at $-22^{\circ} \mathrm{C}$ and kept for a month.

In the first experiment, the IVDMD of the 12 feeds was determined and compared with the control where fresh RF was used. For the other treatments the tubes containing frozen RF were removed from the liquid nitrogen tank and deep freezer, and placed in a water bath at $39^{\circ} \mathrm{C}$ for $30-45$ seconds to thaw. The test feed samples and buffers were then added according to the IVDMD procedure of Tilley \& Terry (1963) and incubated for $48 \mathrm{~h}$. All the steps were performed anaerobically under $\mathrm{CO}_{2}$.

Following the results of the first experiment, the effect of length of incubation on the digestibility of the roughages was investigated in a second experiment. In this trial roughage samples were cryoprotected with 5\% DMSO and kept in the deep freeze. This RF and fresh RK as control were used in the in vitro digestibility phase of the study. IVDMD of the roughages after incubation periods of 60, 72 and 96 h was compared with those subjected to the $48 \mathrm{~h}$ incubation period.

Procedures of the AOAC (1999) were applied for determining dry matter (DM), ash and crude protein (CP). The acid detergent fibre (ADF) and neutral detergent fibre (NDF) analyses were done using the methods of Van Soest et al. (1991). Data of experiment I (five treatments, 12 feeds and five replicates; total 300 tubes) and experiment II (four treatments, six feeds and five replicates; total 120 tubes) were analyzed in 
a completely randomized design using GLM procedure of SAS (1989). The means of results were compared using the Tukey test.

\section{Results and Discussion}

The chemical composition of the test feeds are shown in Table 1. Effects of treatments on IVDMD of feeds in the first experiment are presented in Table 2. Usage of frozen RF resulted in lower $(\mathrm{P}<0.05)$ IVDMD values for roughages compared to fresh RF (control). In both preserving methods with DMSO as cryoprotectant, similar IVDMD values to that of the control were obtained. The IVDMD values of all commercial compound feeds frozen in liquid nitrogen with DMSO were found to be similar to the values of the control $(\mathrm{P}>0.05)$. The deep freeze DMSO group also had similar value to the control group for some of the compound feeds, but not all of them. The Tilley \& Terry (1963) IVDMD procedure, using cryoprotectants to preserve RF with different freezing techniques, has not been studied and reported in the literature. However, Luchini et al. (1996a; b) compared the proteolytic activity of lyophilized and frozen ruminal microorganisms with glycerol, and indicated that glycerol addition had no effect on proteolytic activity of the preserved microorganisms. Hervas et al. (2005) used RF as inoculum source in the gas production technique using an ice bath at $0{ }^{\circ} \mathrm{C}$ for 3,6 and $24 \mathrm{~h}$ and frozen at $-18{ }^{\circ} \mathrm{C}$ for $24 \mathrm{~h}$. While the control and frozen RF in the ice bath at $0^{\circ} \mathrm{C}$ for 3 or $6 \mathrm{~h}$ had similar gas production values, RF held in ice or frozen at $-18^{\circ} \mathrm{C}$ for $24 \mathrm{~h} \mathrm{RF}$ had lower values than the control. They concluded that it might be due to intra cellular ice crystal formation and deformation of the live microbial cells. Preservation of protozoa using freezing methods has been investigated more frequently than the preserving of RF. Freezing ruminal protozoa using 5\% DMSO had high survival rates (Kisidayova et al., 2005; 2006). Abdel-Aziz et al. (2007) evaluated cyropreservation of rumen ciliates with a two-step freezing technique using 4, 5 and 6\% DMSO, glycerol and ethylene glycol as cryoprotectants. The highest percentage of viable protozoa was produced with the usage of DMSO at each concentration level. In addition, Nsabimana et al. (2003) found 5\% DMSO as the optimum cryoprotectant concentration. The present study is in line with previous studies which indicated that DMSO was a more effective cryoprotectant than glycerol. De la Fuente et al. (2006) and Abdel-Aziz et al. (2007) demonstrated that DMSO produced significantly higher viability $(\mathrm{P}<0.05)$ than glycerol. In the present study DMSO as a cryoprotectant revealed a higher IVDMD than glycerol. The higher

Table 1 The chemical composition of the experimental feeds (g/kg dry matter, DM)

\begin{tabular}{lcccccc}
\hline \multicolumn{1}{c}{ Feeds } & DM & OM & Ash & CP & NDF & ADF \\
\hline Barley straw & 937 & 890 & 110 & 35 & 795 & 489 \\
Wheat straw & 937 & 881 & 119 & 33 & 809 & 534 \\
Lentil Straw & 931 & 858 & 142 & 64 & 595 & 407 \\
Wheat silage & 918 & 920 & 80 & 91 & 594 & 358 \\
Maize silage & 924 & 858 & 142 & 90 & 653 & 370 \\
Lucerne & 937 & 897 & 103 & 113 & 623 & 363 \\
Comm. dairy Com. Feed 1. & 880 & 897 & 103 & 230 & 494 & 180 \\
Comm. dairy Com. Feed 2. & 898 & 902 & 98 & 220 & 425 & 182 \\
Comm. Beef Com. Feed 1. & 876 & 916 & 84 & 161 & 515 & 168 \\
Comm. Beef Com. Feed 2. & 887 & 903 & 97 & 173 & 471 & 130 \\
Comm. Ram Lamb Com. Feed. & 882 & 924 & 76 & 167 & 460 & 162 \\
Comm. Lamb Finishing Com. Feed & 879 & 904 & 96 & 179 & 508 & 135
\end{tabular}

$\mathrm{OM}$ - organic matter; CP - crude protein; NDF - neutral detergent fibre; ADF - acid detergent fibre. 
Table 2 The effects of treatments on in vitro dry matter digestibility (IVDMD) of feedstuffs

\begin{tabular}{|c|c|c|c|c|c|c|}
\hline Feeds & Control & $\begin{array}{c}\text { Liquid } \\
\text { nitrogen } \\
5 \% \text { glycerol }\end{array}$ & $\begin{array}{c}\text { Liquid } \\
\text { nitrogen } \\
\text { 5\% DMSO }\end{array}$ & $\begin{array}{l}\text { Deep freezer } \\
5 \% \text { glycerol }\end{array}$ & $\begin{array}{l}\text { Deep freezer } \\
5 \% \text { DMSO }\end{array}$ & s.e.m. \\
\hline Barley straw & $52.0^{\mathrm{a}}$ & $35.1^{d}$ & $46.2^{\mathrm{b}}$ & $42.5^{\mathrm{c}}$ & $46.5^{\mathrm{b}}$ & 0.65 \\
\hline Wheat straw & $43.7^{\mathrm{a}}$ & $29.0^{c}$ & $41.0^{\mathrm{a}}$ & $35.3^{\mathrm{b}}$ & $36.4^{\mathrm{b}}$ & 0.63 \\
\hline Lentil Straw & $57.0^{\mathrm{a}}$ & $43.8^{\mathrm{d}}$ & $52.2^{\mathrm{b}}$ & $48.9^{\mathrm{c}}$ & $53.7^{\mathrm{b}}$ & 0.65 \\
\hline Wheat silage & $65.4^{\mathrm{a}}$ & $51.9^{\mathrm{d}}$ & $61.2^{\mathrm{b}}$ & $56.4^{\mathrm{c}}$ & $61.8^{\mathrm{b}}$ & 0.56 \\
\hline Maize silage & $64.9^{\mathrm{a}}$ & $52.8^{\mathrm{d}}$ & $62.3^{\mathrm{b}}$ & $55.5^{\mathrm{c}}$ & $62.3^{\mathrm{b}}$ & 0.42 \\
\hline Lucerne & $63.1^{\mathrm{a}}$ & $47.1^{\mathrm{d}}$ & $58.6^{\mathrm{b}}$ & $51.4^{\mathrm{c}}$ & $59.2^{\mathrm{b}}$ & 0.42 \\
\hline Comm. dairy Com. Feed 1. & $81.5^{\mathrm{a}}$ & $77.5^{\mathrm{b}}$ & $81.4^{\mathrm{a}}$ & $75.7^{\mathrm{b}}$ & $82.3^{a}$ & 0.76 \\
\hline Comm. dairy Com. Feed 2. & $81.8^{a}$ & $75.7^{c}$ & $81.1^{\mathrm{ab}}$ & $75.9^{c}$ & $78.4^{\mathrm{bc}}$ & 0.71 \\
\hline Comm. Beef Com. Feed 1. & $82.3^{\mathrm{a}}$ & $81.6^{\mathrm{a}}$ & $82.0^{\mathrm{a}}$ & $78.7^{\mathrm{b}}$ & $82.4^{\mathrm{a}}$ & 0.63 \\
\hline Comm. Beef Com. Feed 2. & $85.7^{\mathrm{a}}$ & $81.0^{\mathrm{b}}$ & $85.2^{\mathrm{a}}$ & $79.9^{\mathrm{b}}$ & $81.9^{\mathrm{b}}$ & 0.67 \\
\hline Comm. Ram Lamb Com. Feed & $85.4^{\mathrm{a}}$ & $82.9^{\mathrm{bc}}$ & $83.4^{\mathrm{ab}}$ & $80.8^{\mathrm{c}}$ & $83.2^{\mathrm{abc}}$ & 0.56 \\
\hline $\begin{array}{c}\text { Comm. Lamb Finishing Com. } \\
\text { Feed }\end{array}$ & $86.3^{\mathrm{a}}$ & $80.0^{\mathrm{C}}$ & $84.5^{a}$ & $80.7^{\mathrm{bc}}$ & $83.7^{\mathrm{ab}}$ & 0.77 \\
\hline
\end{tabular}

efficacy of DMSO over glycerol as a cryoprotectant might be attributed to its rapid penetration of cells (Hubalek, 2003; De la Fuente et al., 2006) and consequent interaction with the intracellular water during rapid cooling, resulting in the majority of the intracellular solution becoming vitrified rather than forming intracellular ice crystals (Nsabimana et al., 2003).

Several cryprotectant studies (Kisidayova et al., 1995; Wolfe \& Bryant, 2001) indicated that toxicity of DMSO occurs at low (1\% to 2\%) and high (7\% to 8\%) DMSO levels, and at high temperatures (above $15{ }^{\circ} \mathrm{C}$ ). Since the toxicity of DMSO to cells increased at high temperatures (Wolfe \& Bryant, 2001), this cryoprotectant should be used at room temperature or at $+4{ }^{\circ} \mathrm{C}$, and equilibration time should be minimized (Nsabimana et al., 2003). In the current study, DMSO was added to RF at $+4{ }^{\circ} \mathrm{C}$; thus the positive effect of DMSO over glycerol can be explained by the low temperature $\left(+4{ }^{\circ} \mathrm{C}\right)$ equilibration condition which is in favour of DMSO.

Table 3 The effects of incrementing incubation lengths of roughages on in vitro dry matter digestibility (IVDMD) with deep frozen rumen fluid (RF) including dimethyl sulfoxide (DMSO)

\begin{tabular}{lccccc}
\hline Feeds & $\begin{array}{c}\text { Control 48 h } \\
\text { (fresh RF) }\end{array}$ & $\begin{array}{c}60 \mathrm{~h} \\
\text { Deep freezer RF } \\
\text { with 5\% DMSO }\end{array}$ & $\begin{array}{c}72 \mathrm{~h} \\
\text { Deep freezer RF } \\
\text { with 5\% DMSO }\end{array}$ & $\begin{array}{c}96 \mathrm{~h} \\
\text { Deep freezer RF } \\
\text { with 5\% DMSO }\end{array}$ & s.e.m. \\
\hline Barley straw & $50.2^{\mathrm{a}}$ & $46.4^{\mathrm{b}}$ & $51.3^{\mathrm{a}}$ & $51.30^{\mathrm{a}}$ & 0.61 \\
Wheat straw & $41.3^{\mathrm{a}}$ & $35.6^{\mathrm{b}}$ & $39.6^{\mathrm{a}}$ & $39.8^{\mathrm{a}}$ & 0.52 \\
Lentil Straw & $56.7^{\mathrm{a}}$ & $51.6^{\mathrm{b}}$ & $55.0^{\mathrm{a}}$ & $54.7^{\mathrm{ab}}$ & 0.77 \\
Wheat silage & $64.4^{\mathrm{b}}$ & $61.3^{\mathrm{c}}$ & $64.8^{\mathrm{b}}$ & $67.7^{\mathrm{a}}$ & 0.50 \\
Maize silage & $63.1^{\mathrm{ab}}$ & $59.4^{\mathrm{c}}$ & $61.7^{\mathrm{bc}}$ & $65.4^{\mathrm{ab}}$ & 0.77 \\
Lucerne & $62.3^{\mathrm{ab}}$ & $58.9^{\mathrm{b}}$ & $61.3^{\mathrm{a}}$ & $63.1^{\mathrm{a}}$ & 0.56 \\
\hline
\end{tabular}

$\overline{\mathrm{a}-\mathrm{c}}$ Means within a row with unlike superscripts differ $(\mathrm{P}<0.05)$; s.e.m. - standard error of means. 
The effects of increasing the length of incubation on IVDMD of roughages by using deep frozen RF with addition of 5\% DMSO in the second experiment are presented in Table 3. For all roughages incubation lengths of $72 \mathrm{~h}$ and $96 \mathrm{~h}$ had IVDMS values similar $(\mathrm{P}>0.05)$ to the control. IVDMD values at $60 \mathrm{~h}$ incubation were found to be lower $(\mathrm{P}<0.05)$ than those of the control. An incubation period of $48 \mathrm{~h}$ has been found to be insufficient for low quality roughages such as straws (Barnes, 1967; Grant et al., 1974; Jones et al., 1998; Omed et al., 2000; Can et al., 2009), and should thus be increased to $72 \mathrm{~h}$ to improve fermentation when alternatives to fresh RF are chosen as inoculum sources. This present study suggests that a $72 \mathrm{~h}$ incubation period should be adequate for determining IVDMD of roughages when frozen RF is used.

\section{Conclusions}

In compound feeds the use of 5\% DMSO as a cryoprotectant with liquid nitrogen freezing showed similar IVDMD values to the control group in which fresh RF was used. However, a lower digestibility was recorded for the compound feeds when glycerol was used as a cryoprotectant. When frozen inoculum is used to measure the IVDMD of roughages, incubation should be $72 \mathrm{~h}$ rather than the standard $48 \mathrm{~h}$. However, additional research is required before frozen RF as an inoculum can be recommended for IVDMD studies.

\section{References}

Abdel-Aziz, H.M., Hassan, H.Y., Abd-El-Raof, Y.M., Abou-Zeina, H.A.A. \& Galbt, S.A., 2007. Trails for cryopreservation of rumen protozoa in sheep. Global Veterinaria 1, 9-16.

AOAC, 1999. Official Methods of Analysis of the Association of Official Analytical Chemists., 16th ed. (5th revision). AOAC International, Gaithersburg, MD, USA.

Barnes, R.E., 1967. Collaborative in vitro rumen fermentation studies on forage substrates. J. Anim. Sci. 26, 1120-1130.

Can, A., Hummel, J., Mobashar, M., Boeser, U. \& Sudekum, K.H., 2009. Comparison of sheep ruminal fluid with sheep and horse faeces as inoculum for in vitro gas production measurements. J. Appl. Anim. Res. 35, 143-148.

Denek, N. \& Can, A., 2007. Use of faecal fluid for dry matter digestibility of ruminant feeds. J. Appl. Anim. Res. 31, 29-32.

De la Fuente, G., Cebria'n, J.A. \& Fondevila, M., 2004. A cryopreservation procedure for the rumen protozoon Entodinium caudatum: estimation of its viability by fluorescence microscopy. Lett. Appl. Microbiol. 38, 164-168.

Grant, R.J., Van Soest, P.J. \& McDowell, R.E., 1974. Influence of rumen fluid source and fermentation time on in vitro true dry matter digestibility. J. Dairy Sci. 57, 1201-1205.

Hervas, G., Frutos, P., Giraldez, F.J., Mora, M.J., Fernandez, B. \& Mantecon, A.R., 2005. Effect of preservation on fermentative activity of rumen fluid inoculum for in vitro gas production techniques. Anim. Feed Sci. Technol. 123, 107-118.

Huba'lek, Z., 2003. Protectants used in the cryopreservation of microorganisms. Cryobiology 46, 205-229.

Jones, R.J., Stoltz, M.A., Meyer, J.H.F. \& Bechaz, F.M., 1998. The effect of rumen fluid storage time on digestive capacity with five forage / browse samples. Trop. Grassl. 32, 270-272.

Kisidayova, S., 1995. Two-step freezing of the rumen ciliate protozoon Entodinium caudatum. J. Microbiol. Methods 22, 185-192.

Kisidayova, S., Varadyova, Z. Michalowski, T. \& Newbold, C.J., 2005. Regeneration of cryoresistance of in vitro rumen ciliate cultures. Cryobiology 51, 76-84.

Kisidayova, S. Michalowski, T. \& Varadyova, Z., 2006. Preliminary results of the regeneration of the in vitro rumen ciliate cultures - Effect of their cytoresistance. Endocytobiosis Cell Res. 17, 146-149.

Krishnamoorthy, U., Sniffen, C.J., Stern, M.D. \& Van Soest, P.J., 1983. Evaluation of a mathematical model of rumen digestion and an in vitro simulation of rumen proteolysis to estimate the rumen-undegraded nitrogen content of feedstuffs. Br. J. Nutr. 50, 555-568.

Luchini, N.D., Broderick, G.A. \& Combs, D.K., 1996a. In vitro determination of ruminal protein degradation using freeze-stored ruminal microorganisms. J. Anim. Sci. 74, 2488-2499.

Luchini, N.D., Broderick, G.A. \& Combs, D.K., 1996b. Preservation of ruminal microorganisms for in vitro determination of ruminal protein degradation. J. Anim. Sci. 74, 1134-1143. 
Mauricio, R.M., Mould, F.L., Dhanoa, M.S., Owen, E., Channa, K.S. \& Theodorou, M.K., 1999. A semiautomated in vitro gas production technique for ruminant feedstuff evaluation. Anim. Feed Sci. Technol. 79, 321-330.

Mauricio, R.M., Owen, E., Mould, F.L., Givens, I., Theodorou, M.K., France, J., Davies, D.R. \& Dhanoa, M.S., 2001. Comparison of bovine rumen liquor and bovine faeces as inoculum for an in vitro gas production technique for evaluating forages. Anim. Feed Sci. Technol. 89, 33-48.

Mazur, P., 1984. Freezing of living cells: mechanisms and implications. Am. J. Physiol. 247, 125-142.

Mould, F.L., 2003. Predicting feed quality—chemical analysis and in vitro evaluation. Field Crops Res. 84, 31-44.

Nsabimana, E., Kisidayova, S., Macheboeuf, D., Newbold, C.J. \& Jouany J.P., 2003. Two-step freezing procedure for cryopreservation of rumen ciliates an effective tool for creation of a frozen rumen protozoa bank. Appl. Environ. Microbiol. 69, 3826-3832.

Omed, H.M., Lovett, D. \& Axford, R.F.E., 2000. Faeces as a source of microbial enzymes for estimating digestibility. In: Forage Evaluation in Ruminant Nutrition. Eds Givens, D.I. \& Owen, E., Axford, R.F.E. \& Omed, H.M., CAB International, Wallingford. pp. 135-154.

SAS, 1989. SAS User's Guide: Statistics, 5th ed. SAS Inc., Cary, N.C., USA.

Tanasawa, I., 1998. Things we do not know about cryopreservation of biological organs. Ann. N. Y. Acad. Sci. 858, 227-234.

Tilley, J.M.A. \& Terry, R.A., 1963. A two-stage technique for in vitro digestion of forage. J. Br. Grassl. Soc. $18,104-111$.

Van der Baan, A., Van Niekerk, W.A., Rethman, N.F.G. \& Coertze, R.J., 2004. The determinarion of digestibility of Atriplex nummularia cv. De Kock (Oldman's saltbush) using different in vitro techniques. S. Afr. J. Anim. Sci. 34 (Suppl. 1), 95-97.

Van Soest, P.J., Robertson, J.B. \& Lewis, B.A., 1991. Methods for dietary fiber, neutral detergent fiber, and nonstarch polysaccharides in relation to animal nutrition. J. Dairy Sci. 74, 3583-3591.

Wolfe, J. \& Bryant, G., 2001. Cellular cryobiology: thermodynamic and mechanical effects. Int. J. Refrig. 24, 438-450. 